09.1

\title{
Разработка системы низкопрофильного дефлектометра комбинированных систем сканирующей зондовой и оптической микроскопии
}

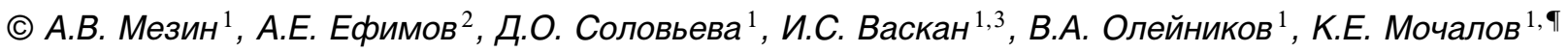 \\ ${ }^{1}$ Институт биоорганической химии им. академиков М.М. Шемякина и Ю.А. Овчинникова РАН, Москва, Россия \\ ${ }^{2}$ Национальный медицинский исследовательский центр трансплантологии и искусственных органов \\ им. акад. В.И. Шумакова Минздрава России, Москва, Россия \\ ${ }^{3}$ Московский физико-технический институт (Национальный исследовательский университет), Долгопрудный, \\ Московская обл., Россия \\ ๑E-mail: mochalov@mail.ru
}

Поступило в Редакцию 9 октября 2020 г.

В окончательной редакции 3 декабря 2020 г.

Принято к публикации 3 декабря 2020 г.

Разработана, изготовлена и испытана система низкопрофильного СЗМ-дефлектометра (СЗМ - сканирующая зондовая микроскопия), позволяющая повысить апертуру подводимых объективов до рекордной на данный момент величины $N A=0.75$. Внедрение такой системы позволит существенно улучшить показатели оптических методик комбинированных систем СЗМ/оптическая микроспектроскопия.

Ключевые слова: сканирующая зондовая микроскопия, оптическая микроспектроскопия, корреляционная микроскопия, СЗМ-дефлектометр.

DOI: 10.21883/PJTF.2021.06.50753.18577

Объединение взаимодополняющих измерительных методик в рамках единого аппаратно-методического комплекса (корреляционная микроскопия, КМ) в последнее десятилетие получило широкое распространение [1-3]. В частности, одним из классических методов КМ стало объединение сканирующей зондовой микроскопии (СЗМ) и оптической микроспектроскопии (ОМ). Несомненным достоинством данного метода является возможность одновременного получения оптических и спектральных данных (все известные методы широкопольной микроскопии и спектроскопии, конфокальная микроскопия, колебательная и флуоресцентная спектроскопия) и данных об ультраструктуре образца методами СЗМ. Кроме того, данный подход позволяет реализовать методы ОМ с пространственным разрешением, преодолевающим дифракционный предел: ближнепольная оптическая микроскопия и зондово-усиленная спектроскопия комбинационного рассеяния (TERS, от англ. tip enhanced Raman scattering) [4]. В частности, новейшей разработкой в данной области является создание уникальной научной установки „Система зондово-оптической 3D корреляционной микроскопии“ (http://ckp-rf.ru/usu/486825/), реализующей методику оптико-зондовой нанотомографии (ОЗНТ) для получения 3D комплементарных данных методами СЗМ и ОМ [5]. Однако основной проблемой КМ этого типа является подвод высокоапертурных объективов к поверхности исследуемого образца с учетом необходимости установки СЗМ-зонда в пространство между ними, что требуется для исследования непрозрачных образцов в „прямой“ конфигурации ОМ. Настоящая работа посвящена решению этой проблемы.
На данный момент предельная числовая апертура подводимых объективов в „прямой“ конфигурации ОМ составляет $N A=0.7$ [6]. При этом, как следует из проведенных нами расчетов, увеличение числовой апертуры до $N A=0.75$, например, для реализации наиболее перспективной ближнепольной методики TERS приводит к почти двукратному увеличению общей эффективности системы возбуждения/сбора вторичного излучения: повышаются эффективность возбуждения $Z$-компоненты электромагнитного поля в области острия TERS-зонда и сбор вторичного излучения согласно дипольному приближению, что является необходимыми условиями реализации TERS [4]. Кроме того, разработка технических решений для подвода более высокоапертурных объективов позволит значительно повысить пространственное разрешение стандартных методик ОМ (конфокальная микроспектроскопия, флуоресцентная микроскопия), реализуемых на уже используемых установках этого типа. В рамках данного исследования мы разработали и изготовили систему, состоящую из держателя СЗМ-зонда и дефлектометра, работающую в составе СЗМ-головки, используемой на установке 3D C3M/OM (ОЗНТ) [7], и позволяющую подвести к плоскости образца объектив „50X Mitutoyo Plan Apo HR Infinity Corrected Objective“" $(N A=0.75$, рабочий отрезок $5.2 \mathrm{~mm}$ ). Столь малый рабочий отрезок указанного объектива накладывает существенные требования на разработку системы держателя СЗМ-зонда и дефлектометра. Соответственно основной задачей, которая решалась при разработке данной системы, было сокращение расстояния между балкой СЗМ-зонда и по- 


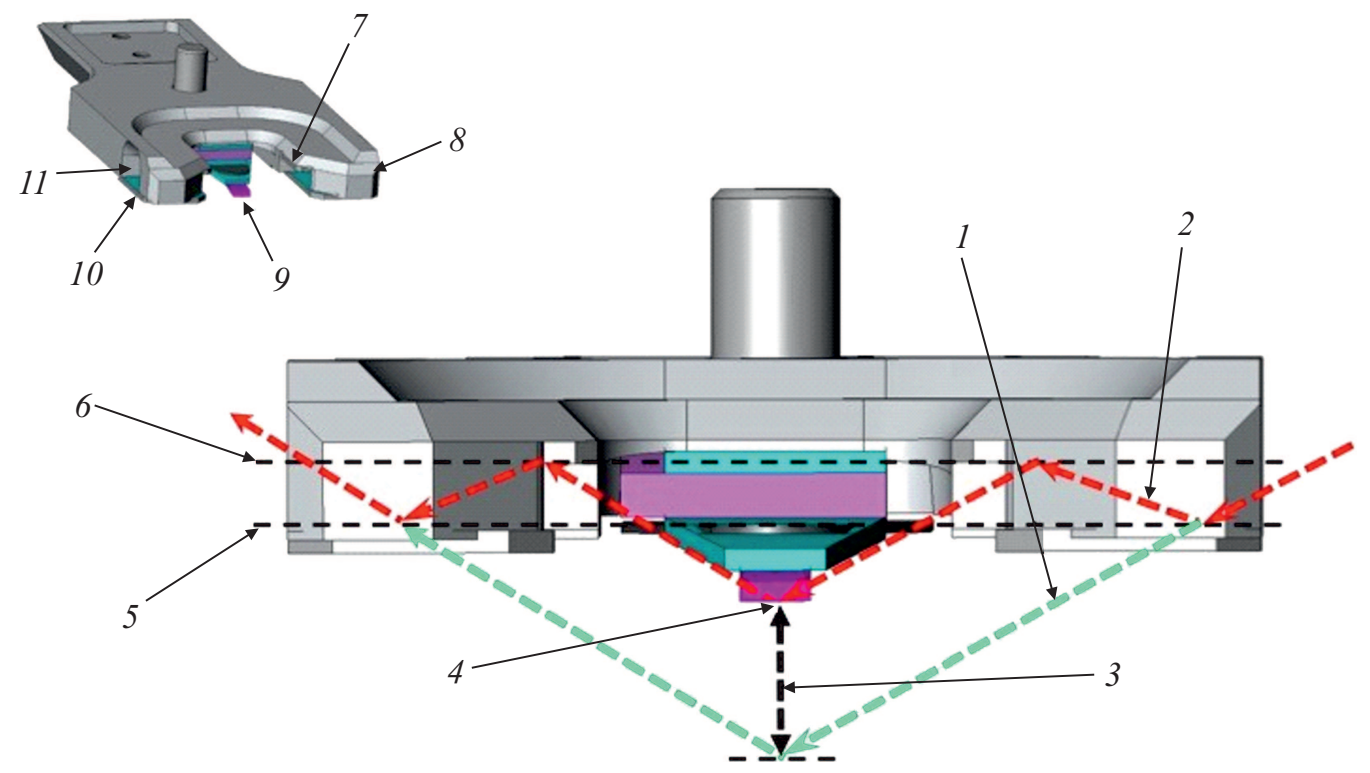

Рис. 1. Принцип работы системы низкопрофильного держателя СЗМ-зонда и дефлектометра. 1 - ход лучей дефлектометра до модификации, 2 - ход лучей дефлектометра после модификации, 3 - вертикальное смещение положения СЗМ-зонда после модификации $(2 \mathrm{~mm}), 4$ - точка отражения падающего излучения на балке СЗМ-зонда, 5 - плоскость нижнего зеркала, 6 плоскость верхнего зеркала, 7 - верхнее зеркало, 8 - входное окно, 9 - СЗМ-зонд, 10 - нижнее зеркало, 11 - выходное окно.

$a$
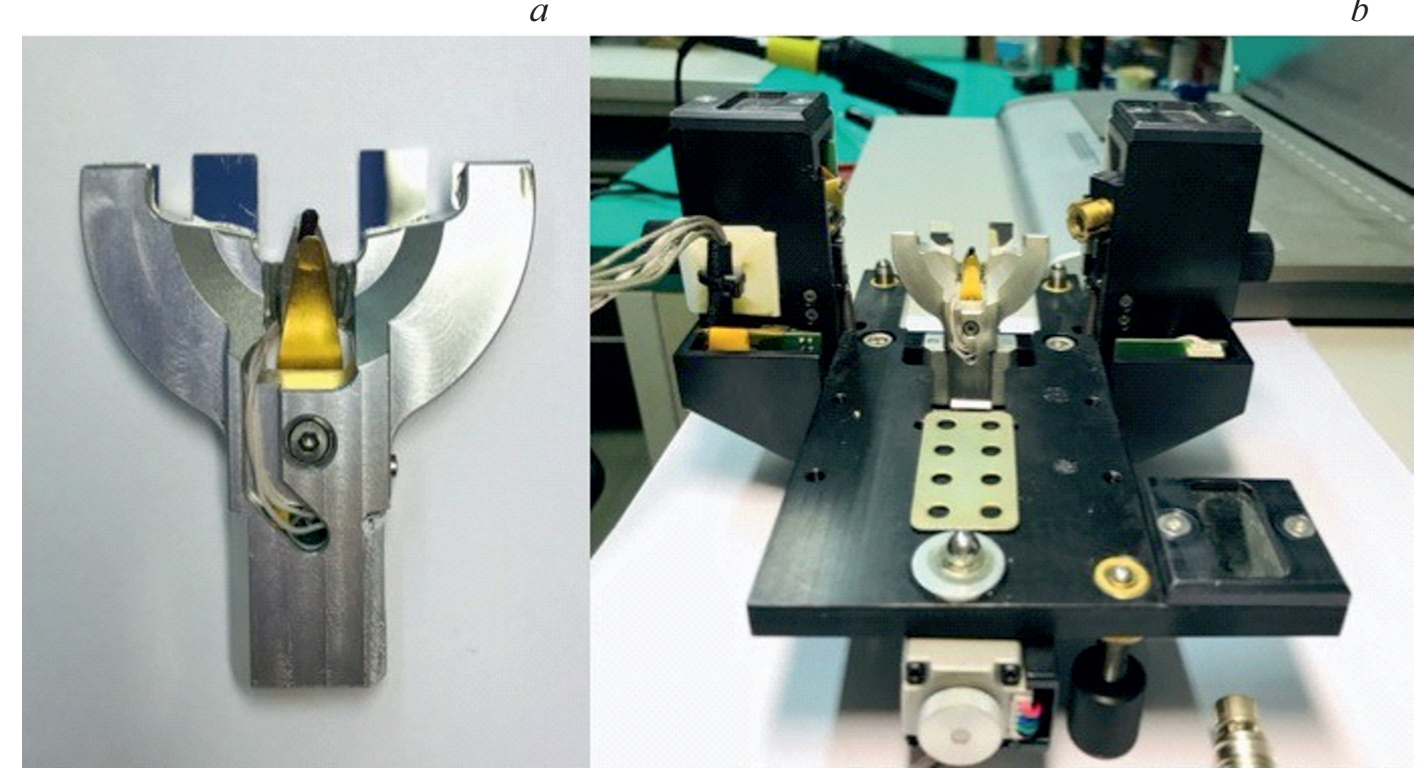

Рис. 2. Изготовленная система низкопрофильного держателя СЗМ-зонда и дефлектометра. $a-$ фотография низкопрофильного держателя СЗМ-зонда, $b$ - фотография низкопрофильного держателя СЗМ-зонда, установленного на СЗМ-головку системы ОЗНТ.

верхностью линзы объектива до расстояния менее $5 \mathrm{~mm}$. Для предыдущей версии дефлектометра эта величина составляла чуть менее $6 \mathrm{~mm}$, что являлось существующим на тот момент техническим пределом. Основной идеей модификации системы дефлектометра была установка двух зеркальных перископов на основной консоли держателя СЗМ-зонда. Эта система зеркал обеспечивает более скользящий эффективный угол падения лучей дефлектометра при сохранении фактического угла паде- ния/отражения на балку зонда (оба по $60^{\circ}$ ) и сохраняет угол и точку выхода/входа из лазерного диода в фотодиод дефлектометра. На рис. 1 схематически показаны изменения, положенные в основу конструкции разработанного низкопрофильного держателя СЗМ-зонда как части системы дефлектометра. Стрелками, помеченными цифрой 2 , показан ход лучей от лазерного диода к фотодиоду дефлектометра после проведения модификации, а стрелками, помеченными цифрой $1,-$ до модификации. 
Видно, что лучи дефлектометра в случае использования низкопрофильного держателя СЗМ-зонда проходят на $2 \mathrm{~mm}$ выше, чем без него, что автоматически означает сокращение рабочего отрезка используемого объектива на эту же величину. На рис. 2 представлены изготовленная система низкопрофильного держателя СЗМ-зонда и дефлектометра $(a)$ и ее закрепление на СЗМ-головке системы ОЗНТ $(b)$. Важно отметить, что в разработанной схеме непосредственной переработке подвергается исключительно держатель СЗМ-зонда, при этом угол и точка выхода/входа лучей из лазерного диода в фотодиод дефлектометра практически не изменяются (рис. 1). Указанное обстоятельство означает, что данная модификация может быть применена и к другим системам СЗМ-головок с открытым доступом для объектива „прямого“ микроскопа, в том числе и выпускающихся серийно [8], без существенного видоизменения их исходной конструкции. Конструкция таких головок в большинстве случаев предполагает использование вытянутых вперед в виде консоли и чаще всего съемных держателей СЗМ-зондов, аналогичных представленному в этой работе. То обстоятельство, что ход лучей от дефлектометра остается прежним, позволит либо впрямую использовать адаптированную версию разработанного нами держателя СЗМ-зонда, либо установить аналогичный перископ на имеющиеся у производителя конструкции.

Таким образом, основным результатом работы являются разработка, изготовление и апробация новой концепции СЗМ-дефлектометра, предназначенного для подвода высокоапертурных $(N A=0.75)$ оптических объективов для комбинированных систем СЗМ/ОМ в режиме „прямого“ микроскопа. Разработанная концепция непосредственно затрагивает только конструкцию держателя СЗМ-зонда и, следовательно, может без особых трудностей быть внедрена в ряде аналогичных промышленно изготавливаемых устройств. Использование данной системы существенно улучшит показатели оптических методик комбинированных систем СЗМ/OM.

\section{Финансирование работы}

Работа выполнена при поддержке Российского научного фонда (проект № 18-19-00718).

\section{Конфликт интересов}

Авторы заявляют, что у них нет конфликта интересов.

\section{Список литературы}

[1] J. Caplan, M. Niethammer, R.M. Taylor II, K.J. Czymmek, Curr. Opin. Struct. Biol., 21 (5), 686 (2011). DOI: 10.1016/j.sbi.2011.06.010

[2] T.L. Burnett, P.J. Withers, Nature Mater., 18, 1041 (2019). DOI: 10.1038/s41563-019-0402-8

[3] B. Joosten, M. Willemse, J. Fransen, A. Cambi, K. van den Dries, Front. Immunol., 9, 1908 (2018). DOI: $10.3389 /$ fimmu.2018.01908
[4] L. Novotny, B. Hecht, Principles of nano-optics, 2nd ed. (Cambridge University Press, Cambridge, 2012), p. 133.

[5] K.E. Mochalov, A.A. Chistyakov, D.O. Solovyeva, A.V. Mezin, V.A. Oleinikov, I.S. Vaskan, M. Molinari, I.I. Agapov, I. Nabiev, A.E. Efimov, Ultramicroscopy, 182, 118 (2017). DOI: 10.1016/j.ultramic.2017.06.022

[6] https://www.ntmdt-si.ru/products/afm-raman-nano-ir-systems/ ntegra-spectra-ii

[7] A.E. Efimov, I.I. Agapov, O.I. Agapova, V.A. Oleinikov, A.V. Mezin, M. Molinari, I. Nabiev, K.E. Mochalov, Rev. Sci. Instrum., 88, 023701 (2017). DOI: 10.1063/1.4975202

[8] http://nanoscantech.com/ru/products/spm/spm-72.html 